Lowe et al., 2008

\title{
MOLECULAR STRESS RESPONSE IN THE CNS OF MICE AFTER SYSTEMIC EXPOSURE TO INTERFERON- $\alpha$, IONIZING RADIATION AND KETAMINE
}

Xiu R Lowe ${ }^{* 1,2,3}$, Francesco Marchetti ${ }^{1}$, Xiaochen Lu $^{2}$, Andrew J. Wyrobek ${ }^{1}$

${ }^{1}$ Life Sciences Division, Lawrence Berkeley National Laboratory, Berkeley, CA

${ }^{2}$ Biosciences Division, Lawrence Livermore National Laboratory, Livermore, CA

${ }^{3}$ Department of Psychiatry, Kaiser Permanente Medical Group, Inc, Hayward, CA

* Corresponding author

Xiu Lowe, M.D., M.S.

Life Sciences Division

Lawrence Berkeley National Laboratory

1 Cyclotron Road

Berkeley, CA 94720

Phone: 510-675-4560

Fax: 510-675-4648

E-MAIL: XRLowe@lbl.gov

Keywords: molecular-response, troponin T1, interferon- $\alpha$, radiation, ketamine, mouse brain, stress marker

Running title: CNS expression of Tnnt 1 after IFN- $\alpha$ and radiation treatment 
Lowe et al., 2008

\begin{abstract}
We previously showed that the expression of troponin T1 (Tnnt 1) was induced in the central nervous system (CNS) of adult mice 30 minutes after treatment with ketamine, a glutamate N-methyl-D-aspartic acid (NMDA) receptor antagonist. We hypothesized that Tnnt 1 expression may be an early molecular biomarker of stress response in the CNS of mice. To further evaluate this hypothesis, we investigated the regional expression of Tnnt 1 in the mouse brain using RNA in situ hybridization four hours after systemic exposure to Interferon- $\alpha$ (IFN- $\alpha$ ) and gamma ionizing radiation, both of which have be associated with wide ranges of neuropsychiatric complications. Adult B6C3F1 male mice were treated with either human IFN- $\alpha$ (a single i.p. injection at $1 \times 10^{5} \mathrm{IU} / \mathrm{kg}$ ) or whole body gamma-radiation (10 cGy or 2 Gy). Patterns of Tnnt 1 transcript expression were compared in various CNS regions after IFN- $\alpha$, radiation (current study) and ketamine treatments. Tnnt 1 expression was consistently induced in pyramidal neurons of cerebral cortex and hippocampus after all treatment regimens including 10 cGy of ionizing radiation. Regional expression of Tnnt 1 was induced in Purkinje cells of cerebellum after ionizing radiation and ketamine treatment; but not after IFN- $\alpha$ treatment. None of the three treatments induced Tnnt 1 expression in glial cells. The patterns of Tnnt 1 expression in pyramidal neurons of cerebral cortex and hippocampus, which are both known to play important roles in cognitive function, memory and emotion, suggest that the expression of Tnnt 1 may be an early molecular biomarker of induced CNS stress.
\end{abstract}


Lowe et al., 2008

\section{Introduction}

Neuropsychiatric diseases are often related to stress and stress modifies the onset and progression of neuropsychiatric diseases (Garcia-Bueno et al., 2008). Current knowledge of stress-induced response in the brain includes regulation of hypothalamic paraventricular nucleus, hypothalamic-pituitary-adrenal axis activity and oxidative/nitrosative, neuroinflammatory changes (Cerqueira et al., 2008). However, the underlying mechanism(s) of stress response in brain are not well understood, nor is it known whether diverse stressors act through common "gatekeeper” molecules or pathways.

IFN- $\alpha$, an anti-viral cytokine (Licinio et al., 1998) is currently used for the treatment of certain viral illnesses, cancers, chronic hepatitis C and other conditions (Wichers et al., 2005; Capuron et al., 2007). There is growing clinical evidence that IFN- $\alpha$ treatment of patients with chronic hepatitis or cancer can cause neuropsychiatric complications (Kraus et al., 2005; Wichers et al., 2005; Capuron et al., 2007). Debien and colleagues (2001) showed that more than $30 \%$ of patients treated by IFN- $\alpha$ presented various psychiatric disorders including depression, anxiety, intense and fluctuating personality disorders, manic or psychotic symptoms, and suicidal tendencies. Others have described declines in concentration, attention, memory and episodic dizzy spells and headaches (Kraus et al., 2005). Yet, the target cells of systemic IFN- $\alpha$ treatment on the neurological and psychiatric effects remain undefined.

There are also growing concerns regarding the cognitive sequelae of whole-brain irradiation for cancer patients (Shi et al., 2006). Gamma-radiation can induce cell death in fetal rat brain (Borovitskaya et al., 1996). Achanta et al., (2007) reported that whole-brain irradiation induced gene expression changes in rodent hippocampus involving pathways important for learning, memory and apoptosis. A study conducted in our laboratory (Yin et al., 2003) demonstrated that whole-body radiation treatment at 10 cGy and 2 Gy modulated the transcript expression of genes in adult mouse brain. The radiation exposure modulated genes related to stress response, cell-cycle control and DNA 
synthesis/repair. Further bioinformatics analyses demonstrated that low-dose radiation (at 10 cGy whole body) affected nine neural signaling pathways, which are also affected in human aging brain and Alzheimer's disease patients (Lowe et al., 2009).

Clinical treatment with glutamate N-methyl-D-aspartic acid (NMDA) receptor antagonists such as ketamine, have been found to induce a broad range of cognitive adverse effects and symptoms that resemble various aspects of neuropsychiatric diseases (Krystal et al., 1994). We have previously demonstrated that Tnnt 1 was dramatically induced in the brain of adult mice 30 minutes after treatment with a single intraperitoneal (i.p.) injection of $80 \mathrm{mg} / \mathrm{kg}$ ketamine (Lowe et al., 2007). Through bioinformatics analysis, Tnnt 1 gene was found to be directly regulated by FoxO1, a transcription factor involved in multiple metabolic pathways including glycolysis, lipogenic and sterol synthentic pathways (Zhang et al., 2006) and central energy homeostasis (Kim et al., 2006). Tnnt 1 is also indirectly regulated by dexamethasone, a known stress marker and a key hormone in energy homeostasis (Wu et al., 2004). Khodarev et al., (2001) showed that modulation of cytoskeleton genes including troponin T1 was induced by irradiation at dose of 1,3 or $10 \mathrm{~Gy}$ in a human malignant gliomas cell line. In addition, PAK3, a GTPase-dependent kinase involved in multiple signaling pathways including axonal guidance signaling, directly interacts with the troponin T complex (Buscemi et al., 2002). These lines of evidence indicated that the function of Tnnt 1 is associated with diverse cellular processes beyond its role in regulating striated muscle contraction.

In vertebrates, troponin $\mathrm{T}$ complex includes three troponin $\mathrm{T}$ (Tnnt) genes that have evolved for the regulation of striated muscle contraction: slow skeleton TnT (sTnT; Tnnt 1), cardiac TnT (cTnT; Tnnt 2), and fast skeleton TnT (fTnT; Tnnt 3) (Wang et al., 2001). However, troponin $T$ is also expressed in non-muscle tissues including prostate cancer cells (Ashida et al., 2004), pancreatic cancer cell lines (Basso et al., 2004), a variety of mammalian cell lines (fibroblasts, foreskin fibroblasts, PtK1 cells, CHO cells and HeLa cells) (Lim et al., 1986), embryonic and neonatal rat brain stems (De Vitry et al., 1994) and in the brain (Fine et al., 1973; Mahendran and Berl, 1977; Lim et al., 1986; Lowe et al., 2007). Thus, it has been speculated that troponin T may function in cellular 
processes other than muscle contraction (Lim et al., 1986). However, its role and function in non-muscle tissues remains unresolved.

We hypothesized that induced Tnnt 1 expression in the brain may be associated with early molecular responses to induced CNS stress. To test this hypothesis, we investigated the effects of systemic exposure to two stressors, IFN- $\alpha$ and ionizing radiation, on Tnnt 1 expression in mouse brain tissues. The aims of this study were to determine whether (a) the expression of Tnnt 1 was induced in CNS of mice by IFN- $\alpha$ or ionizing radiation, both of which are known to induce neuropsychiatric symptoms; (b) there were similar expression patterns compared to those induced by ketamine and (c) there were tissue and cellular-specific expression patterns. Our results showed at the first time, that the all three exposures induced the CNS expression of Tnnt 1 and suggest that Tnnt 1 may have a role as a common molecular biomarker of CNS stress. 
Lowe et al., 2008

\section{Materials and Methods}

Animals and treatment

B6C3F1 male mice were purchased from Harlan Sprague Dawley (Indianapolis, IN). The use of animals in the study was approved by the Lawrence Livermore National Laboratory IACUC.

\section{Interferon- $\alpha$ treatment}

Eight to eleven-week-old male B6C3F1 mice were treated with $0.5 \mathrm{~mL}$ of either distilled water $(n=4)$ as controls or human recombinant interferon- $\alpha$ (Sigma-Aldrich, USA) at $1 \times 10^{5} \mathrm{IU} / \mathrm{kg}$ diluted in distilled water $(\mathrm{n}=4)$, via a single intraperitoneal (i.p.) injection. The dose of IFN- $\alpha$ at $1 \times 10^{5} \mathrm{IU} / \mathrm{kg}$, which is within the range of treatment doses in murine(Makino et al., 2000; Yamano et al., 2000), reportedly induced the serotonin transport mRNA at 3 hours post treatment in vitro (Morikawa et al., 1998). The mice were deeply anaesthetized by Aerrane (isoflurane) inhalant at four hour post-treatment and brain tissues were fixed by cardiac perfusion with $4 \%$ paraformaldehyde (Kim et al., 2000).

\section{Gamma radiation treatment}

Eight to ten-week-old male B6C3F1 mice (one per dose) were exposed to whole-body irradiation at either $10 \mathrm{cGy}$ or 2 Gy gamma-radiation using a ${ }^{137} \mathrm{Cs}$ source with $5 \mathrm{X}$ attenuation at a dose-rate of $0.64 \mathrm{~Gy} \mathrm{~min}^{-1}$. One mouse was sham-irradiated as control. The dose of $10 \mathrm{cGy}$ is roughly equivalent to 20 cranial serial computed tomography (CT) scans (Nickoloff and Alderson, 2001), while 2 Gy is the most commonly used daily dose in radiation therapy (Yin et al., 2003; Brenner and Hall, 2007). Mice were euthanized with $\mathrm{CO}_{2}$ at four hour post-treatment. Brains were surgically removed and frozen on dry ice, then fixed with $4 \%$ paraformaldehyde.

\section{RNA in situ hybridization}

Brain tissue sections from eleven mice ( 8 for INF- $\alpha$ and 3 for radiation treatment), in sagittal and coronal planes, were isolated, fixed overnight, and paraffin embedded. Serial 
sections were cut at $5 \mu \mathrm{m}$ thickness. An antisense riboprobe was generated as described by Lowe et al.,(2007). Briefly, the transcribed region of mouse Tnnt 1 (GeneBank AJ 131711) was amplified using PCR with a pair of forward (5'GAAGCGCATGGAGAAAGACT-3’) and reverse (3’TGCGGTCTTTTAGTGCAATG-5’) primers. The initial PCR product was further amplified with the same forward primer and T7-tag reverse primer (3'TAATACGACTCACTATAGGG TGCGGTCTTTTAGTGCAATG-5’). The second PCR product was purified with phenol/chloroform and washed with TE on a microson100 (Amicon, http://www.millipore.com) and concentrated to $1 \mu \mathrm{g} / \mathrm{ul}$. One $\mu \mathrm{g}$ of template DNA was used to generate the antisense RNA probe using in vitro transcription with T7 polymerase and biotinylated UTP (Roche, Biotin RNA labeling kit, CA). Three paraffin embedded slides per mouse were concurrently hybridized for each treatment group. One slide was hybridized without antisense Tnnt 1 probe as a negative control for the hybridization procedure. Hybridizations were performed at $37^{\circ} \mathrm{C}$ over night in a humidified chamber according to the standard protocol (DAKO, Carpinteria, CA). Antibiotin antibody at 1:100 dilution was used as a primary antibody and was incubated with the sections at room temperature for one hour. Antimouse Broadspectrum antibody conjugated with HRP without the dilution (Zymed, San Francisco, CA) was used as a secondary antibody and was incubated with the sections at room temperature for 15 minutes. AEC substrate was used for color development and hematoxylin was used for counterstaining. The duration of color developing was identical for every slide that was hybridized concurrently.

\section{Image acquisition and analysis}

Three replicate slides per mouse were analyzed under the microscope, and the two with most consistent signal patterns, were digitally scanned for data analysis (Aperio Images, https://www.aperio.com). One control mouse (C4) showed high levels of Tnnt 1 expression in all regions of the brain, which was confirmed by repeated hybridization (data not shown). Thus, it was considered an outlier and excluded from further analysis. The scanned images without further modification or enhancement were then manually analyzed on the computer or on high resolution printed images. The entire image was 
reviewed. The cytoplasmic staining of Tnnt 1 was visually classified into four categories: "negative” (no signal at all) and "positive” (if any signals) in control mice; "induced” and "not induced" (with respect to the controls) in treated mice. Specific regions and cells were compared between controls and treated animals within each treatment and compared among three different treatments: IFN- $\alpha$ and radiation (current study) or ketamine (Lowe et al., 2007).

\section{Validation of RNA expression}

Brain tissue sections from mice treated with ketamine at $80 \mathrm{mg} / \mathrm{kg}$ and concurrent controls (Lowe et al., 2007) were examined for protein expression of Tnnt 1. Ketamine was injected via i.p. (Lowe et al., 2007) because most injectable anesthetics, such as ketamine are easy to administer by the i.p. route in mice. Injectable anesthetics can be administered i.p., s.c., i.m. or i.v, which are all acceptable, according to a Laboratory Mouse manual book (Hedrich and Bullock, 2004). Fluorescence immunohistochemistry staining was used according to manufactory protocol (DAKO, Carpinteria, CA). Briefly, goat antimouse troponin T1 (Santa Cruz Biotechnology, Inc. Santa Cruz, CA) at 1:50 dilution was used as primary antibody and was incubated with sections at $4^{0} \mathrm{C}$ over night. Rabbit antigoat AlexaFluor 594 (Invitrogen Corp, USA) at 1:300 dilution was used as secondary antibody and was incubated with sections at room temperature for 45 minutes. 4,6diamidino-2-phenylindole (DAPI) was used for the nuclei counterstaining. Florescence images were obtained as described previously by (Lowe et al., 2001). 
Lowe et al., 2008

\section{Results}

Two groups of adult male mice were treated with either single i.p. injection of IFN- $\alpha$ or whole-body radiation. Various brain sections of mice were tested for the expression of Tnnt 1 using RNA in situ hybridization at four hours post treatment. Expression of Tnnt 1 was significantly induced in various CNS regions of mice treated with IFN- $\alpha$ and in mice treated with irradiation when compared with concurrent sham exposed controls.

\section{CNS expression of troponin T1 was induced after IFN- $\alpha$ treatment}

Tnnt 1 RNA probe labeled with biotin was hybridized to brain tissue sections prepared from mice (eight total) treated with IFN- $\alpha$ or distilled water (as control). The control mice showed unique regional expression patterns for the Tnnt 1 gene (Table 1): i.e., positive expression in the choroid plexus epithelium cells, ependymal lining of ventricles, and in the Ammon's horn of hippocampus region (Fig. 1, far right panel of $3^{\text {rd }}$ row) and no detectable expression (negative) in pyramidal neurons and other regions. These findings are consistent with our previously reported baseline expression of Tnnt 1 in untreated mice (Lowe et al., 2007).

IFN- $\alpha$ treatment induced the expression of Tnnt 1 above baseline level (Fig. 1, top two rows) in Ammon's horn region (CA1 - CA3 represent the region of Ammon's horn), and in the dentate gyrus (DG) region (far left panels of bottom two rows) of hippocampus. The expression of Tnnt 1 was also induced in pyramidal neurons of the cerebral cortex and confined to cytoplasm of pyramidal neurons ( $3^{\text {rd }}$ column of bottom two rows). The signals detected in the choroid plexus epithelium cells of IFN- $\alpha$-treated mice were much stronger than those of the control mice (Fig. 1, far right panels of bottom two rows). However, little expression of Tnnt 1 was induced in the Purkinje cells of the cerebellum (Fig. 1, $2^{\text {nd }}$ columns of bottom two rows). In comparison, the expression of Tnnt 1 was not induced in glial cells of cerebral cortex by IFN- $\alpha$ treatment.

Whole body radiation induced the expression of troponin $T 1$ in adult mouse brain 
The expression patterns of Tnnt 1 in the control mouse (Fig. 2, far right panel of the top row) were consistent with those found in the controls of IFN- $\alpha$ treatment group (current study) and the controls of ketamine exposure group (Lowe et al., 2007). Both low dose (10 cGy) and high dose (2 Gy) radiation exposures significantly induced the expression of Tnnt 1 in hippocampus (Fig. 2, $1^{\text {st }}$ column), Purkinje cells of the cerebellum (Fig. 2, $2^{\text {nd }}$ column) and pyramidal neurons of the cerebral cortex (Fig. 2, $3^{\text {rd }}$ column) when compared with those of sham-radiated ( 0 Gy) mouse (Fig. 2, top row). As for IFN- $\alpha$, the signals detected in the choroid plexus epithelium cells of irradiated mice were much stronger than those of the control (Fig. 2, far right panel of the middle row). The intensities of induced Tnnt 1 expression were similar in all regions for both radiation doses (Fig. 2, $2^{\text {nd }}$ and $3^{\text {rd }}$ rows). In addition, the expression of Tnnt 1 was significantly induced in Ammon's horn (CA1-CA3) and DG regions of hippocampus at comparable levels, as illustrated by the similar intensity of signals in both regions (Fig. 2 first column; Fig. 3, first two columns of $3^{\text {rd }}$ row). As for IFN- $\alpha$, radiation treatment did not induce the expression of Tnnt 1 in glial cells of cerebral cortex.

\section{Comparison of induced expression patterns of Tnnt 1 in adult mouse brain}

Patterns of Tnnt 1 expression induced by ketamine (Lowe et al., 2007), IFN- $\alpha$ and radiation (current study) are compared in Table 1. The expression of Tnnt 1 was consistently induced in pyramidal neurons of the cerebral cortex and in hippocampus by all three exposures (Table 1, Fig. 3), but not in the glial cells. The cerebellum was significantly affected by ketamine, less affected by radiation, and almost not affected by IFN- $\alpha$ treatment (Fig. 3, $3^{\text {rd }}$ column). The expression of Tnnt 1 in the Purkinje cells of the cerebellum was significantly induced by ketamine and irradiation treatment, but not by IFN- $\alpha$ treatment (Fig. 3, $3^{\text {rd }}$ column). Within the hippocampus region, the expression of Tnnt 1 in the dentate gyrus (DG) region was as strong as in the CA1-CA3 region only after radiation exposure (Fig. 3, first two columns). The variation of Tnnt 1 expression patterns among three treatments may be due to the dose used for each agent in the study.

\section{Validation of RNA expression of Tnnt 1}


Using fluorescence immunohistochemistry staining, we confirmed that the protein expression of Tnnt 1 was induced in mice treated with ketamine (Lowe et al., 2007) in the Purkinje cells, pyramidal neurons and in hippocampus region as showed in Fig. 4, A. The patterns of protein expression of Tnnt 1 in CNS were consistent with those of RNA expression of Tnnt 1 (Lowe et al., 2007; Fig. 4 B), which validates the induction of Tnnt 1 expression in CNS of mice treated with ketamine. 
Lowe et al., 2008

\section{Discussion}

Systemic IFN- $\alpha$ treatment and whole-body radiation induced the expression of Tnnt 1 in adult mouse brain

Using RNA in situ hybridization, we demonstrated that the expression of Tnnt 1 was consistently induced in pyramidal neurons of cerebral cortex and hippocampus, but not in glial cells after IFN- $\alpha$, whole-body radiation, as well as ketamine treatment. IFN- $\alpha$ apparently had nearly no effect on Purkinje cells of cerebellum, while radiation treatment had similar effects in both regions of Ammon's horn and DG of hippocampus, in contrast to IFN- $\alpha$ and ketamine. Using fluorescence immunohistochemistry staining, we confirmed the expression of Tnnt 1 protein after ketamine treatment. The patterns of protein expression of Tnnt 1 in CNS were consistent with those of RNA expression of Tnnt 1.

Cognitive impairment and mood disorders are well recognized but poorly understood sequelae of IFN- $\alpha$ therapy (Valentine and Meyers, 2005). Several authors have speculated that the pathophysiologic mechanisms include indirect action via hypothalamus through hypothalamic-pituitary-adrenal (HPA) and hypothalamic-thyroidadrenal (HTA) axes; via neurotransmitter pathways (serotonin, dopamine or opioid); or via cytokine pathways (Licinio et al., 1998; Yamano et al., 2000; Valentine and Meyers, 2005). IFN- $\alpha$ may also cross the blood-brain barrier via circumventricular organs (Licinio et al., 1998). Wang et al., (2008) provided evidence that mouse IFN- $\alpha$, circulating systemically, can enter the CNS and act in the brain locally through signal transducers and activators of transcription (STAT1). The expression of IFN-stimulated genes (ISGs) was significantly increased as early as two hours, and peaked around eight hours, before returning to basal levels at $24 \mathrm{~h}$ post treatment (Wang et al., 2008). Here, we reported that systemic IFN- $\alpha$ administration induced CNS expression of Tnnt 1 , which provide novel molecular evidence of IFN- $\alpha$ therapy sequelae in central nervous system. 
Therapeutic radiation of the brain is associated with a number of adverse effects, including cognitive impairment (Tada et al., 2000). Schatz et al., (2000) showed that deficits in processing speed and working memory following cranial radiation therapy may underlie declines in IQ. Low doses of irradiation can lead to cognitive dysfunction without inducing significant morphological changes (Abayomi, 1996). Such cognitive changes are often manifested as deficits in hippocampal-dependent functions of learning, memory, and spatial information processing (Mizumatsu et al., 2003). We have shown that the expression of troponin T1 was significantly induced by whole-body irradiation at doses of 10 cGy or $2 \mathrm{~Gy}$ in two sub-regions of the hippocampus: the dentate gyrus (DG) and Ammon's horn, in addition to other regions of the mouse brain (Fig. 2). However, in a microarray analysis where the coronal sections of mouse brain were used, Yin et al., (2003) did not report the induced-expression of Tnnt 1 by the same radiation treatment regimen. The discrepancy between the current study and that of Yin et al., (2003) may be related to the tissue sections used in the microarray analysis and resulting in decreased sensitivity when the entire coronal section, rather than a specific sub-region, was used by Yin et al., (2003).

\section{Comparison of induced Tnnt 1 expression patterns in adult mouse brain}

The expression of Tnnt 1 was induced in pyramidal neurons of the cerebral cortex by all three treatments. Pyramidal neurons are abundant in the cerebral cortex of virtually every mammal that has ever been studied. They are found primarily in structures that are associated with advanced cognitive functions (Spruston, 2008). The properties of pyramidal neurons are likely to be crucial for synaptic integration and plasticity (Spruston, 2008). It is well known that the cerebral cortex plays a key role in memory, attention, perceptual awareness and consciousness (Elston, 2003). Our finding that these exogenous insults induced the expressions of Tnnt 1 in pyramidal neurons suggested that expression of Tnnt 1 may be a common and early response to CNS stress.

Although the pathogenesis of radiation-induced cognitive injury is unknown, it may involve loss of neural precursor cells from the subgranular zone (SGZ) of the hippocampal dentate gyrus and alterations in new cell production (neurogenesis) 
(Mizumatsu et al., 2003). We discovered that whole-body radiation treatment (at dose of 10 cGy and 2 Gy), significantly induced similar intensities of Tnnt 1 expression in both the CA1-CA3 and the dentate gyrus regions of the hippocampus (Fig. 2 and 3), while these phenomena were not observed after ketamine or IFN- $\alpha$ treatment (Table 1, Fig. 3). Our data raises the question of whether radiation-induced Tnnt 1 expression in DG of the hippocampus is associated with neurogenesis, which will require further study of precursor neural cells after radiation exposure. In addition, it is known that radiation therapy poses the risk of neurotoxicity in clinical setting. However, we do not have data to differentiate whether the expression of Tnnt1 induced by 10 cGy and 2 Gy is associated with neurotoxicity in current study. Future investigation is indicated to explore this relationship.

The neuropsychiatric complications associated with IFN- $\alpha$ treatment are well known, but the neurobiological correlates of these side effects are undetermined (Licinio et al., 1998; Valentine and Meyers, 2005). Pathophysiological changes have been linked to various brain regions including cerebral cortex, prefrontal cortex, hippocampus, basal ganglia and cerebellum. Thus far, these findings are not consistent in literature (Juengling et al., 2000; Capuron et al., 2007; Wang et al., 2008). We found that IFN- $\alpha$ induced Tnnt 1 expression in cerebral cortex and hippocampus regions in all mice tested. However, IFN- $\alpha$ had no apparent effect on the expression of Tnnt 1 in Purkinje cells of the cerebellum (Fig. 1 and Fig.3), in contrast to the findings with ketamine or irradiation exposures (Table 1). The CNS sequelae of IFN- $\alpha$ therapy are not significantly associated with movement disorders (Valentine and Meyers, 2005), which may underlie our observation of negative induction of Tnnt 1 in cerebellum, whose function mainly involves coordination and control of voluntary movement (Miall and Reckess, 2002).

The doses of radiation and IFN- $\alpha$ used in the current study, as well as that of ketamine (Lowe et al., 2007), were within the therapeutic ranges. Slikker et al.,(2007) and Wang and Slikker (2008) reported that single subcutaneously injection of ketamine at $40 \mathrm{mg} / \mathrm{kg}$ induced modulation of 18 genes at one hour post treatment. Those genes were specifically associated with apoptosis. Hayase et al., (2006) observed that "a single dose 
of KT (ketamine) caused hyperlocomotion in a low (30 mg/kg, i.p.) dose group, and hypolocomotion followed by hyperlocomotion in a high (100 mg/kg, i.p.) dose group” in mice. Xu et al., (2007) reported the optimizing anesthetic dosage of ketamine in murine as at $100 \mathrm{mg} / \mathrm{kg}$. Nakki et al., (1996) illustrated that a single dose of $40 \mathrm{mg} / \mathrm{kg}$ of ketamine was needed to induce HSP70 expression compared with that needed to produce microglial activation ( $80 \mathrm{mg} / \mathrm{kg}$ ), at 1-5 days post-treatment. HSP70 expression serves to protect the neurons from further injury while microglial activation is a marker of neural injury (Nakki et al., 1996). Our experiments were performed using a single dose of 80 $\mathrm{mg} / \mathrm{kg}$ at 30 min post-treatment (Lowe et al., 2007), which allowed us to detect early and common molecular stress response in CNS of mice.

The significance of Tnnt 1 expression in adult mouse brain induced by various insults We have presented new evidence here that expression of Tnnt 1 can be induced in CNS by systemic treatment of IFN- $\alpha$ or whole-body radiation. The common response of CNS expression of Tnnt 1 was in pyramidal neurons of cerebral cortex and hippocampus after treatment of IFN- $\alpha$ and radiation, as well as ketamine (Lowe et al., 2007). These three agents are known to be associated with neuropsychiatric complications. The modulation of Tnnt 1 expression in brain may be associated with a generalized damage response to environmental stress. Our data imply that CNS expression of Tnnt 1 may have a role as an early molecular biomarker of CNS stress.

The molecular significance of induced expression of Tnnt 1 in brain tissue in response to environmental insults and stress may be related to calcium homeostasis. Troponin $\mathrm{T}$ is the subunit of troponin complex and interacts with tropomyosin, troponin C, troponin I and F-actin. Tnnt 1 is known to have higher $\mathrm{Ca}^{2+}$ affinity as compared with other subunits in peripheral tissues (Kischel et al., 2005). There is evidence that calcium homeostasis, especially in the context of the central nervous system, may have crucial implications in many neuropsychiatric conditions (Yarlagadda, 2002). Mobilization of calcium, both extra- and intracellularly, has tremendous implications in the brain because of its buffering capacity and its second messenger functions (Yarlagadda, 2002; Eguiagaray et al., 2004). It will be interesting to explore whether the up-regulated Tnnt 1 expression is a 
transient stress response after exogenous insults or portends persistent damage or cascade pathways changes that lead to neuropsychiatric diseases observed in the patients treated with these agents.

Future studies are warranted to investigate the expression profiles of Tnnt 1 induction by various neuropsychiatric associated agents using various expression technologies to explore the roles of pathway interactions in the central nervous system, and to further characterize the role of Tnnt 1 as a CNS stress marker, and its associated CNS damage response functions. 
Lowe et al., 2008

\section{Acknowledgments}

We thank Ms. Sylvia Ahn for the technical assistance of RNA in situ hybridization; Dr. Eric Yin (PhD) for mouse radiation treatment and brain tissues collection after radiation.

This work was performed under the auspices of the U.S. Department of Energy by the University of California, Lawrence Berkeley National Laboratory under contract DEAC02-05CH11231 and Lawrence Livermore National Laboratory under contract W7405-ENG-48. Funded in part by DOE Low Dose Research Program grant (SCW0391) to AJW. 
Lowe et al., 2008

\section{References}

Abayomi OK (1996) Pathogenesis of irradiation-induced cognitive dysfunction. Acta oncologica (Stockholm, Sweden) 35:659-663.

Achanta P, Thompson KJ, Fuss M, Martinez JL, Jr. (2007) Gene expression changes in the rodent hippocampus following whole brain irradiation. Neuroscience letters 418:143-148.

Ashida S, Nakagawa H, Katagiri T, Furihata M, Iiizumi M, Anazawa Y, Tsunoda T, Takata R, Kasahara K, Miki T, Fujioka T, Shuin T, Nakamura Y (2004) Molecular features of the transition from prostatic intraepithelial neoplasia (PIN) to prostate cancer: genome-wide gene-expression profiles of prostate cancers and PINs. Cancer research 64:5963-5972.

Basso D, Millino C, Greco E, Romualdi C, Fogar P, Valerio A, Bellin M, Zambon CF, Navaglia F, Dussini N, Avogaro A, Pedrazzoli S, Lanfranchi G, Plebani M (2004) Altered glucose metabolism and proteolysis in pancreatic cancer cell conditioned myoblasts: searching for a gene expression pattern with a microarray analysis of 5000 skeletal muscle genes. Gut 53:1159-1166.

Borovitskaya AE, Evtushenko VI, Sabol SL (1996) Gamma-radiation-induced cell death in the fetal rat brain possesses molecular characteristics of apoptosis and is associated with specific messenger RNA elevations. Brain Res Mol Brain Res 35:19-30.

Brenner DJ, Hall EJ (2007) Computed tomography--an increasing source of radiation exposure. The New England journal of medicine 357:2277-2284.

Buscemi N, Foster DB, Neverova I, Van Eyk JE (2002) p21-activated kinase increases the calcium sensitivity of rat triton-skinned cardiac muscle fiber bundles via a mechanism potentially involving novel phosphorylation of troponin I. Circulation research 91:509-516.

Capuron L, Pagnoni G, Demetrashvili MF, Lawson DH, Fornwalt FB, Woolwine B, Berns GS, Nemeroff CB, Miller AH (2007) Basal ganglia hypermetabolism and symptoms of fatigue during interferon-alpha therapy. Neuropsychopharmacology 32:2384-2392.

Cerqueira JJ, Almeida OF, Sousa N (2008) The stressed prefrontal cortex. Left? Right! Brain, behavior, and immunity.

De Vitry F, Hillion J, Catelon J, Gros F (1994) Myogenic cells in the rat embryonic brain stem. Comptes rendus de l'Academie des sciences 317:332-340.

Debien C, De Chouly De Lenclave MB, Foutrein P, Bailly D (2001) [Alpha-interferon and mental disorders]. L'Encephale 27:308-317.

Eguiagaray JG, Egea J, Bravo-Cordero JJ, Garcia AG (2004) [Neurotransmitters, calcium signalling and neuronal communication]. Neurocirugia (Asturias, Spain) 15:109118.

Elston GN (2003) Cortex, cognition and the cell: new insights into the pyramidal neuron and prefrontal function. Cereb Cortex 13:1124-1138.

Fine RE, Blitz AL, Hitchcock SE, Kaminer B (1973) Tropomyosin in brain and growing neurones. Nature: New biology 245:182-186. 
Garcia-Bueno B, Caso JR, Leza JC (2008) Stress as a neuroinflammatory condition in brain: Damaging and protective mechanisms. Neuroscience and biobehavioral reviews.

Hayase T, Yamamoto Y, Yamamoto K (2006) Behavioral effects of ketamine and toxic interactions with psychostimulants. BMC Neurosci 7:25.

Hedrich HJ, Bullock GR (2004) The Laboratory Mouse: Part of the Handbook of Experimental Animals By Contributor, Hans J. Hedrich, Gillian R. Bullock, : Academic Press, page 556 - 559.

Juengling FD, Ebert D, Gut O, Engelbrecht MA, Rasenack J, Nitzsche EU, Bauer J, Lieb K (2000) Prefrontal cortical hypometabolism during low-dose interferon alpha treatment. Psychopharmacology 152:383-389.

Khodarev NN, Park JO, Yu J, Gupta N, Nodzenski E, Roizman B, Weichselbaum RR (2001) Dose-dependent and independent temporal patterns of gene responses to ionizing radiation in normal and tumor cells and tumor xenografts. Proceedings of the National Academy of Sciences of the United States of America 98:1266512670.

Kim J, Noskov VN, Lu X, Bergmann A, Ren X, Warth T, Richardson P, Kouprina N, Stubbs L (2000) Discovery of a novel, paternally expressed ubiquitin-specific processing protease gene through comparative analysis of an imprinted region of mouse chromosome 7 and human chromosome 19q13.4. Genome research 10:1138-1147.

Kim MS, Pak YK, Jang PG, Namkoong C, Choi YS, Won JC, Kim KS, Kim SW, Kim HS, Park JY, Kim YB, Lee KU (2006) Role of hypothalamic Foxo1 in the regulation of food intake and energy homeostasis. Nature neuroscience 9:901906.

Kischel P, Bastide B, Muller M, Dubail F, Offredi F, Jin JP, Mounier Y, Martial J (2005) Expression and functional properties of four slow skeletal troponin $\mathrm{T}$ isoforms in rat muscles. American journal of physiology 289:C437-443.

Kraus MR, Schafer A, Wissmann S, Reimer P, Scheurlen M (2005) Neurocognitive changes in patients with hepatitis $C$ receiving interferon alfa-2b and ribavirin. Clinical pharmacology and therapeutics 77:90-100.

Krystal JH, Karper LP, Seibyl JP, Freeman GK, Delaney R, Bremner JD, Heninger GR, Bowers MB, Jr., Charney DS (1994) Subanesthetic effects of the noncompetitive NMDA antagonist, ketamine, in humans. Psychotomimetic, perceptual, cognitive, and neuroendocrine responses. Archives of general psychiatry 51:199-214.

Licinio J, Kling MA, Hauser P (1998) Cytokines and brain function: relevance to interferon-alpha-induced mood and cognitive changes. Seminars in oncology 25:30-38.

Lim SS, Hering GE, Borisy GG (1986) Widespread occurrence of anti-troponin T crossreactive components in non-muscle cells. Journal of cell science 85:1-19.

Lowe X, Bhattacharya S, Marchetti F, Wyrobek A (2009) Early brain response to lowdose radiation exposure involves molecular networks and pathways associated with cognitive functions, advanced aging, and Alzheimer's disease. Radiation research (in press). 
Lowe X, Eskenazi B, Nelson DO, Kidd S, Alme A, Wyrobek AJ (2001) Frequency of XY sperm increases with age in fathers of boys with Klinefelter syndrome. American journal of human genetics 69:1046-1054.

Lowe XR, Lu X, Marchetti F, Wyrobek AJ (2007) The expression of Troponin T1 gene is induced by ketamine in adult mouse brain. Brain research 1174:7-17.

Mahendran C, Berl S (1977) Isolation of troponin-like complex from bovine brain cortex. Proceedings of the National Academy of Sciences of the United States of America 74:2273-2277.

Makino M, Kitano Y, Komiyama C, Hirohashi M, Takasuna K (2000) Involvement of central opioid systems in human interferon-alpha induced immobility in the mouse forced swimming test. British journal of pharmacology 130:1269-1274.

Miall RC, Reckess GZ (2002) The cerebellum and the timing of coordinated eye and hand tracking. Brain and cognition 48:212-226.

Mizumatsu S, Monje ML, Morhardt DR, Rola R, Palmer TD, Fike JR (2003) Extreme sensitivity of adult neurogenesis to low doses of X-irradiation. Cancer research 63:4021-4027.

Morikawa O, Sakai N, Obara H, Saito N (1998) Effects of interferon-alpha, interferongamma and cAMP on the transcriptional regulation of the serotonin transporter. European journal of pharmacology 349:317-324.

Nakki R, Nickolenko J, Chang J, Sagar SM, Sharp FR (1996) Haloperidol prevents ketamine- and phencyclidine-induced HSP70 protein expression but not microglial activation. Exp Neurol 137:234-241.

Nickoloff EL, Alderson PO (2001) Radiation exposures to patients from CT: reality, public perception, and policy. Ajr 177:285-287.

Schatz J, Kramer JH, Ablin A, Matthay KK (2000) Processing speed, working memory, and IQ: a developmental model of cognitive deficits following cranial radiation therapy. Neuropsychology 14:189-200.

Shi L, Adams MM, Long A, Carter CC, Bennett C, Sonntag WE, Nicolle MM, Robbins M, D'Agostino R, Brunso-Bechtold JK (2006) Spatial learning and memory deficits after whole-brain irradiation are associated with changes in NMDA receptor subunits in the hippocampus. Radiation research 166:892-899.

Slikker W, Jr., Paule MG, Wright LK, Patterson TA, Wang C (2007) Systems biology approaches for toxicology. J Appl Toxicol 27:201-217.

Spruston N (2008) Pyramidal neurons: dendritic structure and synaptic integration. Nature reviews 9:206-221.

Tada E, Parent JM, Lowenstein DH, Fike JR (2000) X-irradiation causes a prolonged reduction in cell proliferation in the dentate gyrus of adult rats. Neuroscience 99:33-41.

Valentine AD, Meyers CA (2005) Neurobehavioral effects of interferon therapy. Current psychiatry reports 7:391-395.

Wang C, Slikker W, Jr. (2008) Strategies and experimental models for evaluating anesthetics: effects on the developing nervous system. Anesth Analg 106:16431658.

Wang J, Campbell IL, Zhang H (2008) Systemic interferon-alpha regulates interferonstimulated genes in the central nervous system. Molecular psychiatry 13:293-301. 
Wang Q, Reiter RS, Huang QQ, Jin JP, Lin JJ (2001) Comparative studies on the expression patterns of three troponin $\mathrm{T}$ genes during mouse development. The Anatomical record 263:72-84.

Wichers MC, Koek GH, Robaeys G, Verkerk R, Scharpe S, Maes M (2005) IDO and interferon-alpha-induced depressive symptoms: a shift in hypothesis from tryptophan depletion to neurotoxicity. Molecular psychiatry 10:538-544.

Wu W, Chaudhuri S, Brickley DR, Pang D, Karrison T, Conzen SD (2004) Microarray analysis reveals glucocorticoid-regulated survival genes that are associated with inhibition of apoptosis in breast epithelial cells. Cancer research 64:1757-1764.

Xu Q, Ming Z, Dart AM, Du XJ (2007) Optimizing dosage of ketamine and xylazine in murine echocardiography. Clin Exp Pharmacol Physiol 34:499-507.

Yamano M, Yuki H, Yasuda S, Miyata K (2000) Corticotropin-releasing hormone receptors mediate consensus interferon-alpha YM643-induced depression-like behavior in mice. The Journal of pharmacology and experimental therapeutics 292:181-187.

Yarlagadda A (2002) Role of calcium regulation in pathophysiology model of schizophrenia and possible interventions. Medical hypotheses 58:182-186.

Yin E, Nelson DO, Coleman MA, Peterson LE, Wyrobek AJ (2003) Gene expression changes in mouse brain after exposure to low-dose ionizing radiation. International journal of radiation biology 79:759-775.

Zhang W, Patil S, Chauhan B, Guo S, Powell DR, Le J, Klotsas A, Matika R, Xiao X, Franks R, Heidenreich KA, Sajan MP, Farese RV, Stolz DB, Tso P, Koo SH, Montminy M, Unterman TG (2006) FoxO1 regulates multiple metabolic pathways in the liver: effects on gluconeogenic, glycolytic, and lipogenic gene expression. The Journal of biological chemistry 281:10105-10117. 


\section{Figure legends}

Figure 1

Comparisons of Tnnt 1 expression in the brains of adult mice treated with the IFN- $\alpha$ (IFN1, IFN2, IFN3, and IFN4) or distilled water (C1, C2, and C3) using RNA in situ hybridization.

Row 1 and 2: (Magnification: 20X). Comparison of Tnnt 1 expression in CA1-CA3 regions of Ammon's horn of hippocampus between controls and IFN- $\alpha$ treated mice. Neg: hybridization without Tnnt 1 RNA probe. Chpl: choroid plexus.

Row 3 and 4: (Magnification: $40 \mathrm{X}$, except $1^{\text {st }}$ column: 10X; $4^{\text {th }}$ column: 20X). Comparison of Tnnt 1 expression between controls (C) and IFN- $\alpha$ treated mice (IFN) in various brain regions. $1^{\text {st }}$ column: hippocampus CA1-CA3 (represent the region of Ammon's horn) and dentate gyrus (DG) regions; $2^{\text {nd }}$ column: cerebellum PC/arrows: Purkinje cells of cerebellum; $3^{\text {rd }}$ column: cerebral cortex, open arrows: pyramidal cells; $4^{\text {th }}$ column: choroid plexus (chpl).

Figure 2

(Magnification: $1^{\text {st }}$ and $4^{\text {th }}$ column: 20X; $2^{\text {nd }}$ and $3^{\text {rd }}$ column: 40X).

Comparisons of Tnnt 1 expression in the brains of adult mice treated with whole-body radiation at dose of 0 Gy ( $1^{\text {st }}$ row $), 10 \mathrm{cGy}\left(2^{\text {nd }}\right.$ row $)$ and 2 Gy ( $3^{\text {rd }}$ row $)$ using RNA in situ hybridization.

CA1-CA3 (represent the region of Ammon's horn) and dentate gyrus (DG) regions; PC/arrows: Purkinje cells of cerebellum; Open arrows: pyramidal cells; chpl: choroid plexus. Neg: hybridization without Tnnt 1 RNA probe.

Figure 3

(Magnification: $40 \mathrm{X}$, except $1^{\text {st }}$ column: 10X).

Tissue and cell-specific expression patterns of Tnnt 1 after systemic treatments of ketamine, IFN- $\alpha$ and radiation. 
K: ketamine treatment;(Lowe et al., 2007) IFN: IFN- $\alpha$ treatment; 10 cGy: radiation treatment. DG: dentate gyrus of hippocampus; CA1-CA3: represent the region of Ammon's horn in hippocampus; Close arrows in $3^{\text {rd }}$ column: Purkinje cells of cerebellum; Open arrows in $4^{\text {th }}$ column: pyramidal cells of cerebral cortex.

Figure 4

(Magnification: 40 X).

Comaprison RNA and protein expression of Tnnt1 in mouse brain treated with ketamine A: Fluorescence immunohistochemistry staining. Fluorescence red cytoplasm staining indicated Tnnt 1 protein expression.

B: RNA in situ hybridization. Brownish cytoplasm staining indicated Tnnt 1 RNA expression.

The indication of arrow's color: white: Purkinje cells; yellow: pyramidal cells; red: hippocampus.

*data from Lowe et al., (2007). 
Lowe et al., 2008

\section{Conflict of Interest statement}

The authors declare that there are no conflicts of interest. 
Fig. 1 Tnnt 1 expression is induced by interferon- $\alpha$ treatment
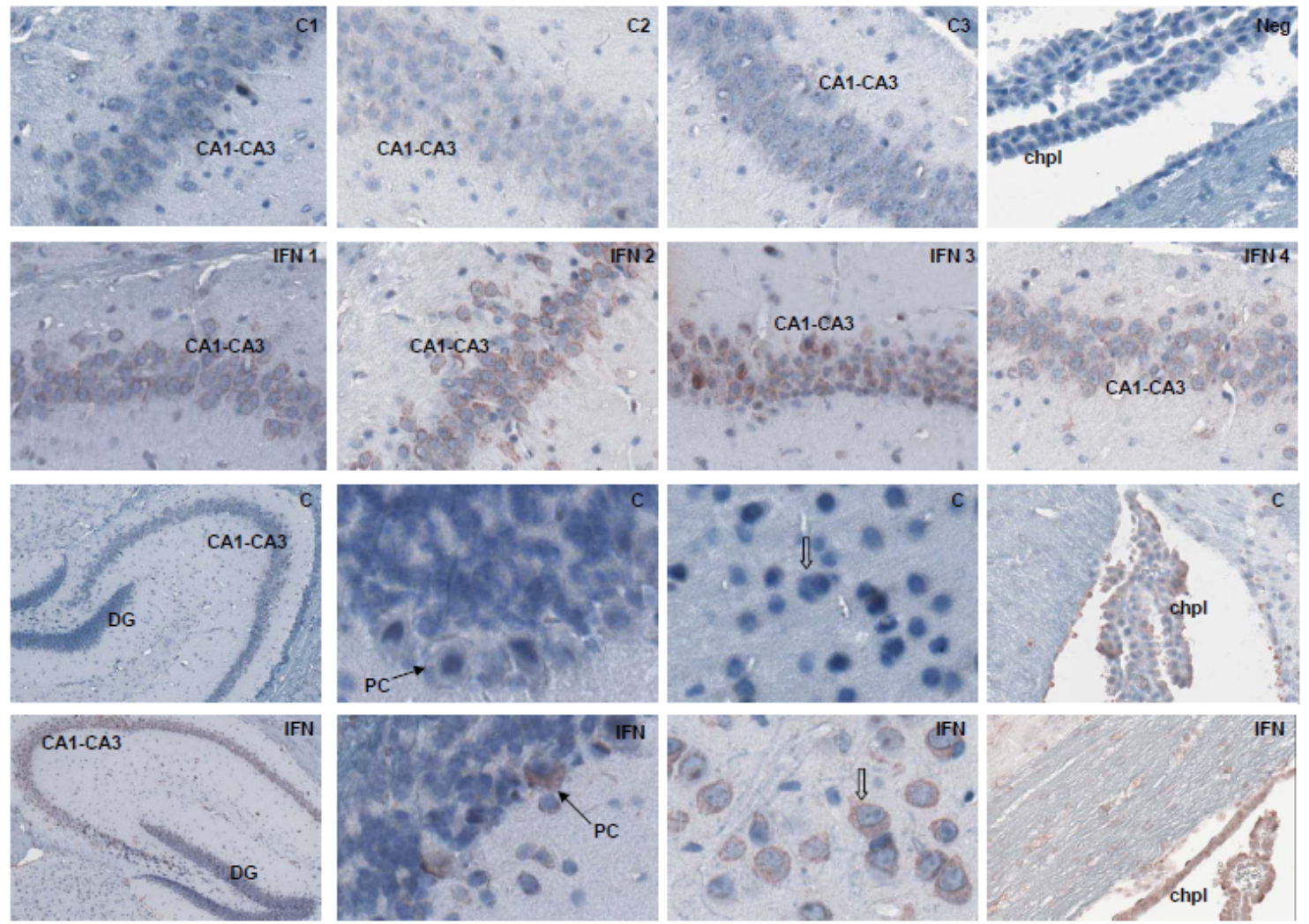
Lowe et al., 2008

Fig. 2 Tnnt 1 expression is induced by ionizing radiation treatment.
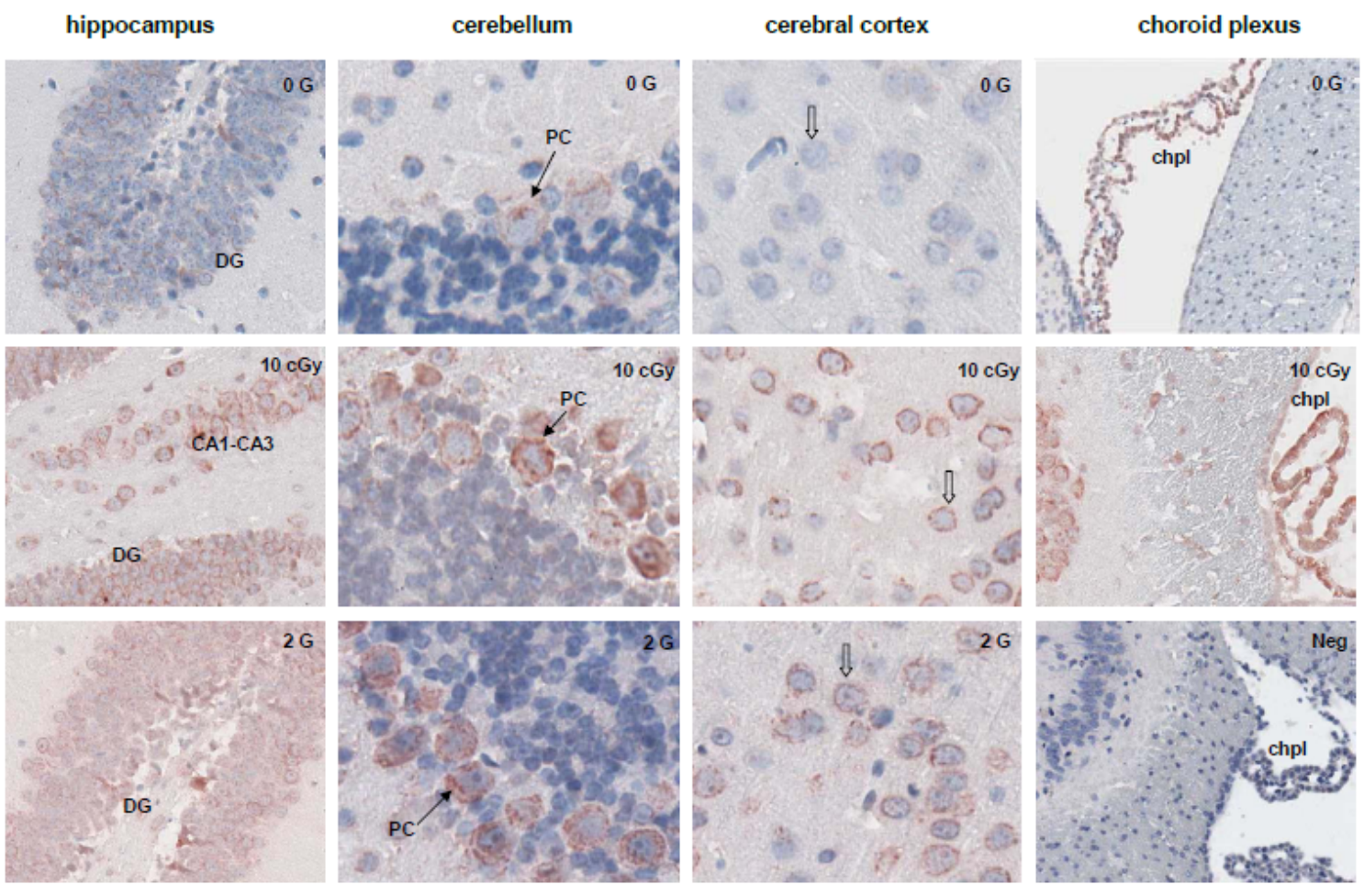
Lowe et al., 2008

Fig. 3 Comparisons of tissue, cell-specific expression patterns of Tnnt 1 induced by various exposures

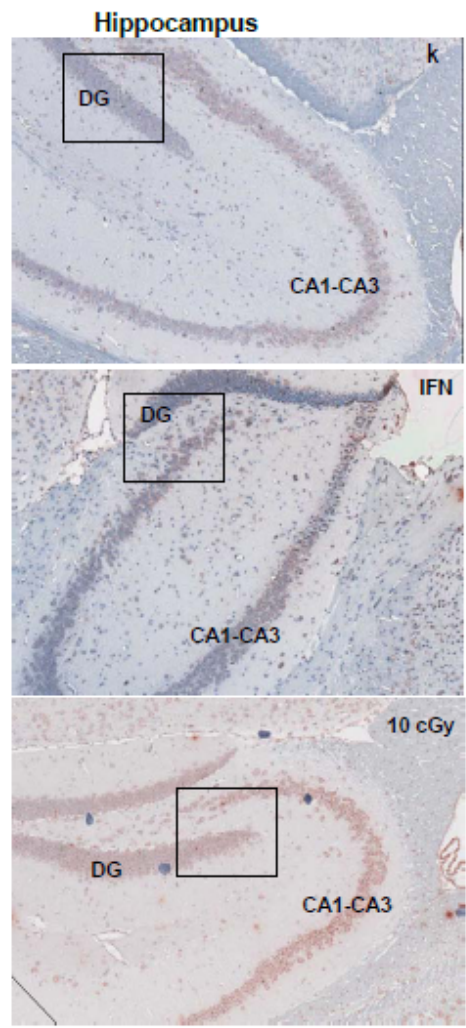
inset of left column
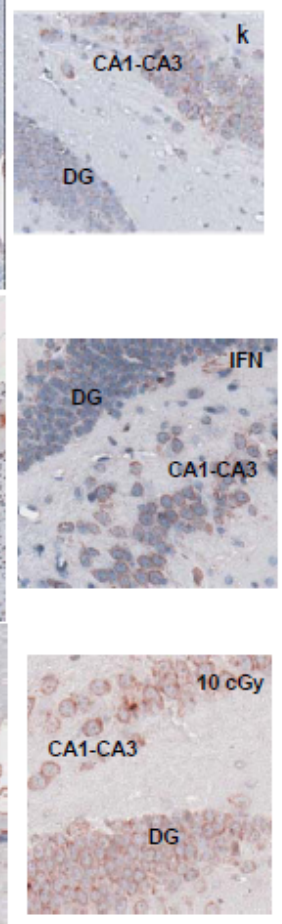

Purkinje cells
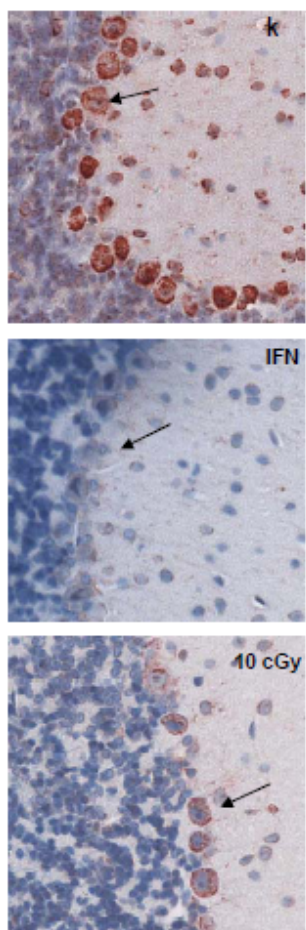

Pyramidal cells
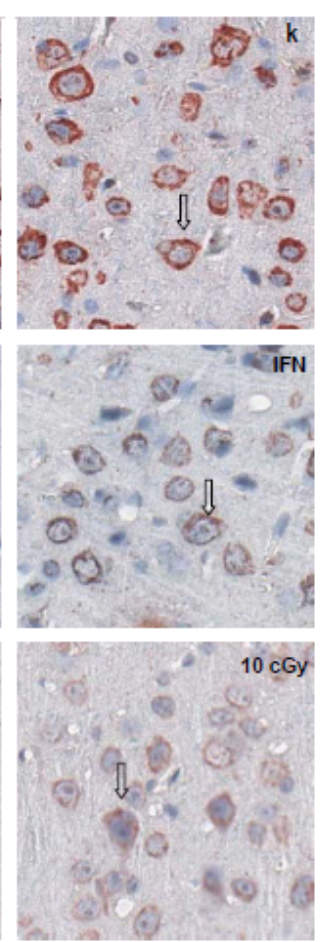
Fig. 4. Comparison of RNA and protein expression of Tnnt1 in mouse brain treated with ketamine

A. Fluorescence immunohistostaining
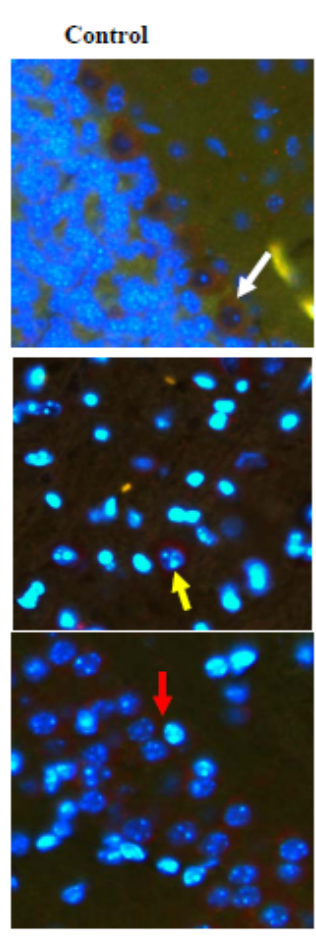

B. In situ RNA hybridization*
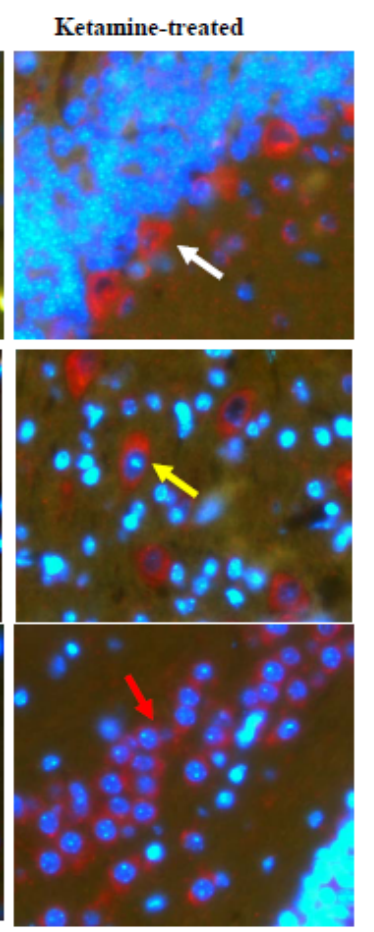

Control
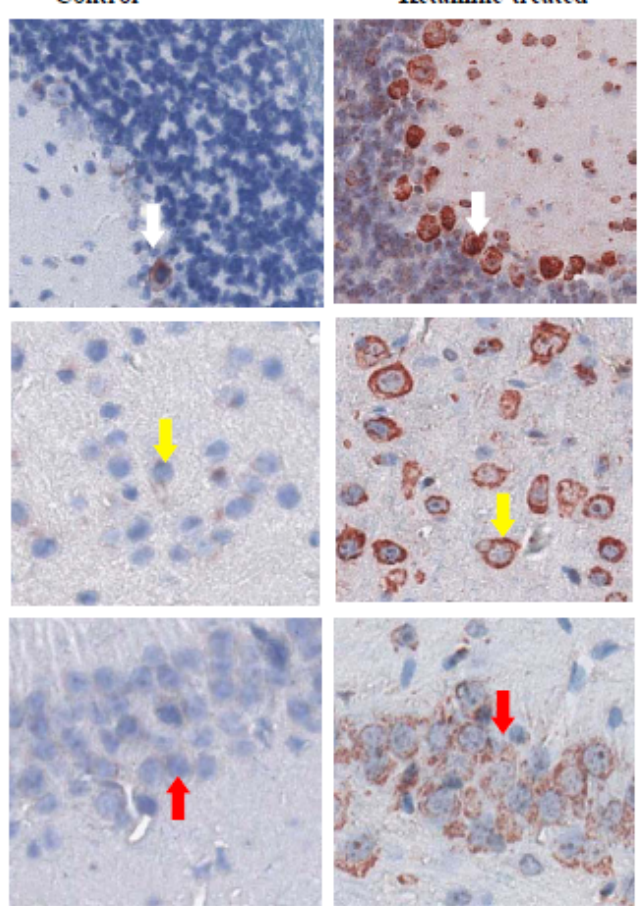
Lowe et al., 2008

Table 1. Comparison of expression patterns of Tnnt 1 in adult mouse brain induced by various exposures*

\begin{tabular}{|c|c|c|c|c|}
\hline & $\begin{array}{c}\text { Controls }^{8} \\
\text { (concurrent) }\end{array}$ & Ketamine ${ }^{* \star}$ & Radiation $* * *$ & Interferon- $\alpha$ \\
\hline $\begin{array}{l}\text { Dose } \\
\text { Time post treatment (hour) }\end{array}$ & $\begin{array}{l}\mathrm{n} / \mathrm{a} \\
\text { concurrent }\end{array}$ & $\begin{array}{l}80 \mathrm{mg} / \mathrm{Kg} \\
0.5\end{array}$ & $10 \mathrm{cGy}, 2$ Gy & $1 \times 10^{5} \mathrm{IU} / \mathrm{Kg}$ \\
\hline \multicolumn{5}{|l|}{ Induced-expression pattern } \\
\hline $\begin{array}{l}\text { Choroid plexus } \\
\text { ependymal lining of ventricles } \\
\text { Hippocampus }\end{array}$ & $\begin{array}{l}\text { positive } \\
\text { positive }\end{array}$ & $\begin{array}{l}\text { induced } \\
\text { induced }\end{array}$ & $\begin{array}{l}\text { induced } \\
\text { induced }\end{array}$ & $\begin{array}{l}\text { induced } \\
\text { induced }\end{array}$ \\
\hline $\begin{array}{l}\text { Ammon's horn (CA1 - CA3 regions) } \\
\text { Dentate gyrus region }\end{array}$ & $\begin{array}{l}\text { positive } \\
\text { negative }\end{array}$ & $\begin{array}{l}\text { induced } \\
\text { induced }\end{array}$ & $\begin{array}{l}\text { induced } \\
\text { induced }\end{array}$ & $\begin{array}{l}\text { induced } \\
\text { induced }\end{array}$ \\
\hline $\begin{array}{l}\text { Ammon's horn (A) vs dentate gyrus region (DG) } \\
\text { Purkinje cells of cerebellum } \\
\text { Pyramidal neurons of cereberal cortex }\end{array}$ & $\begin{array}{l}A>D G \\
\text { negative } \\
\text { negative }\end{array}$ & $\begin{array}{l}\text { A }>\text { DG } \\
\text { induced } \\
\text { induced }\end{array}$ & $\begin{array}{l}A=D G \\
\text { induced } \\
\text { induced }\end{array}$ & $\begin{array}{l}\mathrm{A}>\mathrm{DG} \\
\text { not induced } \\
\text { induced }\end{array}$ \\
\hline Glial cells & negative & not induced & not induced & not induced \\
\hline
\end{tabular}

* RNA expression of Tnnt 1 by CNS regions: in unexposed animals: "positive"-RNA is detectable; "negative"- RNA is not detactable.

** Data from Lowe et al.,(2007).

*** Similar response in $10 \mathrm{cGy}$ and 2 Gy animals, compared to control.

${ }^{5}$ All concurrent controls showed similar expression patterns. n/a: not applicable. 